\title{
Pathogenicity of Nectriaceous Fungi on Avocado in Australia
}

\author{
Louisamarie E. Parkinson, Roger G. Shivas, and Elizabeth K. Dann ${ }^{\dagger}$
}

First and third authors: Queensland Alliance for Agriculture and Food Innovation, The University of Queensland, and second author: Plant Pathology Herbarium, Biosecurity Queensland, Department of Agriculture and Fisheries, Ecosciences Precinct, 41 Boggo Road, Dutton Park, QLD 4102, Australia.

Accepted for publication 17 July 2017.

\begin{abstract}
Black root rot is a severe disease of young avocado trees in Australia causing black necrotic roots, tree stunting, and leaf drop prior to tree death. Nectriaceous fungi (Nectriaceae, Hypocreales), are commonly isolated from symptomatic roots. This research tested the pathogenicity of 19 isolates from Calonectria, Cylindrocladiella, Dactylonectria, Gliocladiopsis, and Ilyonectria, spp. collected from young avocado trees and other hosts. Glasshouse pathogenicity tests with 'Reed' avocado (Persea americana) seedlings confirmed that Calonectria ilicicola is a severe pathogen of avocado, causing stunting, wilting, and seedling death within 5 weeks of inoculation. Isolates of C. ilicicola from peanut, papaya, and custard apple were also shown to be aggressive pathogens of avocado,
\end{abstract}

ABSTRACT

Black root rot is a severely damaging disease of young avocado (Persea americana, family Lauraceae) trees caused by soilborne nectriaceous fungi (Nectriaceae, Hypocreales) (Dann et al. 2012; Ramírez-Gil and Morales-Osorio 2013; Vitale et al. 2012). Symptoms of black root rot in young avocado trees include tree stunting, wilt, leaf chlorosis and browning, leaf drop, and rapid decline and death of young orchard transplants (Fig. 1) (Dann et al. 2012). Affected roots have brown to black, sunken lesions which coalesce to destroy the root completely (Fig. 1).

Infected nursery trees have been reported to die within 1 to 5 years of transplantation into orchards, causing significant commercial loss in Australia (Dann et al. 2012), Chile (Besoain and Piontelli 1999), Colombia (Ramírez-Gil and Morales-Osorio 2013), Israel (Zilberstein et al. 2007), Italy (Vitale et al. 2012), and New Zealand (Boesewinkel 1986). Species confirmed by pathogenicity tests as the cause of black root rot in avocado include Calonectria ilicicola in Australia (Dann et al. 2012), which also caused severe stunting, and Dactylonectria macrodidyma (as Ilyonectria macrodidyma) in Italy (Vitale et al. 2012). I. liriodendri and an undescribed Gliocladiopsis sp. were not pathogenic to avocado seedlings in glasshouse pathogenicity tests (Dann et al. 2012). Other fungi have been reported associated with black root rot of avocado, including Cylindrocladiella parva (Crous et al. 1991; Dann et al. 2012), Gliocladiopsis peggii, G. whileyi, and G. forsbergii (Parkinson et al. 2017).

There are reports of $I$. destructans as a pathogen of avocado (as Cylindrocarpon destructans in Besoain and Piontelli 1999; Darvas 1978; Ramírez-Gil and Morales-Osorio 2013; and as Neonectria radicicola in Zilberstein et al. 2007). The first report of $I$. destructans isolated from avocado was from South Africa (Darvas 1978); later, it was found in Chile, where 22,000 nursery trees were killed between 1994 and 1995 (Besoain and Piontelli 1999). More recently, I. destructans has been reported in avocado seedlings in Israel (Zilberstein et al.

†Corresponding author: E. K. Dann; E-mail: e.dann@uq.edu.au

(C) 2017 The American Phytopathological Society demonstrating a broad host range. An isolate of a Calonectria sp. from blueberry and avocado isolates of Dactylonectria macrodidyma, $D$. novozelandica, D. pauciseptata, and $D$. anthuriicola caused significant root rot but not stunting within 5 to 9 weeks of inoculation. An isolate of an Ilyonectria sp. from grapevine closely related to Ilyonectria liriodendri, and avocado isolates of Cylindrocladiella pseudoinfestans, Gliocladiopsis peggii, and an Ilyonectria sp. were not pathogenic to avocado.

Additional keywords: Dactylonectria novozelandica, Dactylonectria pauciseptata, Ilyonectria liriodendri.

2007) and Columbia (Ramírez-Gil and Morales-Osorio 2013). However, conclusive evidence of pathogenicity and accurate identification of the causal agent was not demonstrated in these studies. That is, confirmation of pathogenicity by demonstrating Koch's postulates were not recorded in the studies of Darvas (1978) or Zilberstein et al. (2007). Moreover, the studies in Colombia had carried out pathogenicity tests and Koch's postulates but relied on morphology alone to identify the fungi (Ramírez-Gil and Morales-Osorio 2013), which potentially risks misidentification of cryptic and closely related species. I. destructans has had numerous taxonomic nomenclature changes over time (Lombard et al. 2015) and correct identification by phylogenetic methods and gene sequencing is important for accurate identification of this species. Thus far, there are no studies that have shown that Ilyonectria spp. are pathogens of avocado.

Dactylonectria is a genus recently separated from Ilyonectria (Lombard et al. 2014, 2015) and a number of species have been reported as soilborne pathogens, including $D$. macrodidyma causing black foot disease of grapevines (as C. macrodidymum in Halleen et al. 2004; and as I. macrodidyma in Agustí-Brisach and Armengol 2013; Cabral et al. 2012; Whitelaw-Weckert et al. 2013) and apple seedling replant disease (Tewoldemedhin et al. 2011b). D. macrodidyma caused significant root rot in $100 \%$ of potted grapevines (Vitis vinifera 'Chardonnay') inoculated with D. macrodidyma in Western Australia (Whitelaw-Weckert et al. 2013). However, D. macrodidyma has never been associated with avocado disease in Australia. Many previous records of Cylindrocarpon spp. on avocado in Australia (Dann et al. 2012) warrant reidentification because these fungi have been recently transferred to other genera, including Cylindrodendrum, Dactylonectria, Ilyonectria, and Neonectria (Lombard et al. 2014, 2015).

Six genera in the family Lauraceae have species that are reported as hosts for Calonectria spp. (Crous 2002; Lombard et al. 2010b), including Persea (Dann et al. 2012) and Laurus (laurels) (Polizzi et al. 2012). Calonectria pauciramosa is reported as a dominant nursery pathogen in Australia (Lombard et al. 2011) and South Africa (Crous 2002; Lombard et al. 2010a, 2011), while C. ilicicola is highly pathogenic to horticultural and field crops, causing several diseases, including red crown rot in soybean (Kuruppu et al. 2004; 
Ochi et al. 2011), Cylindrocladium black rot of peanut (Wright et al. 2010), collar rot of papaya (Male et al. 2012), crown and root rot of bay laurel (Polizzi et al. 2012), and leaf spot in holly (Ilex aquifolium) (Lechat et al. 2010). Damage caused by C. ilicicola is reported to be as high as $50 \%$ yield loss in both peanut (Wright et al. 2010) and soybean (Kuruppu et al. 2004). The ability of nectriaceous pathogens of other crops to infect and cause disease in avocado is yet to be investigated.
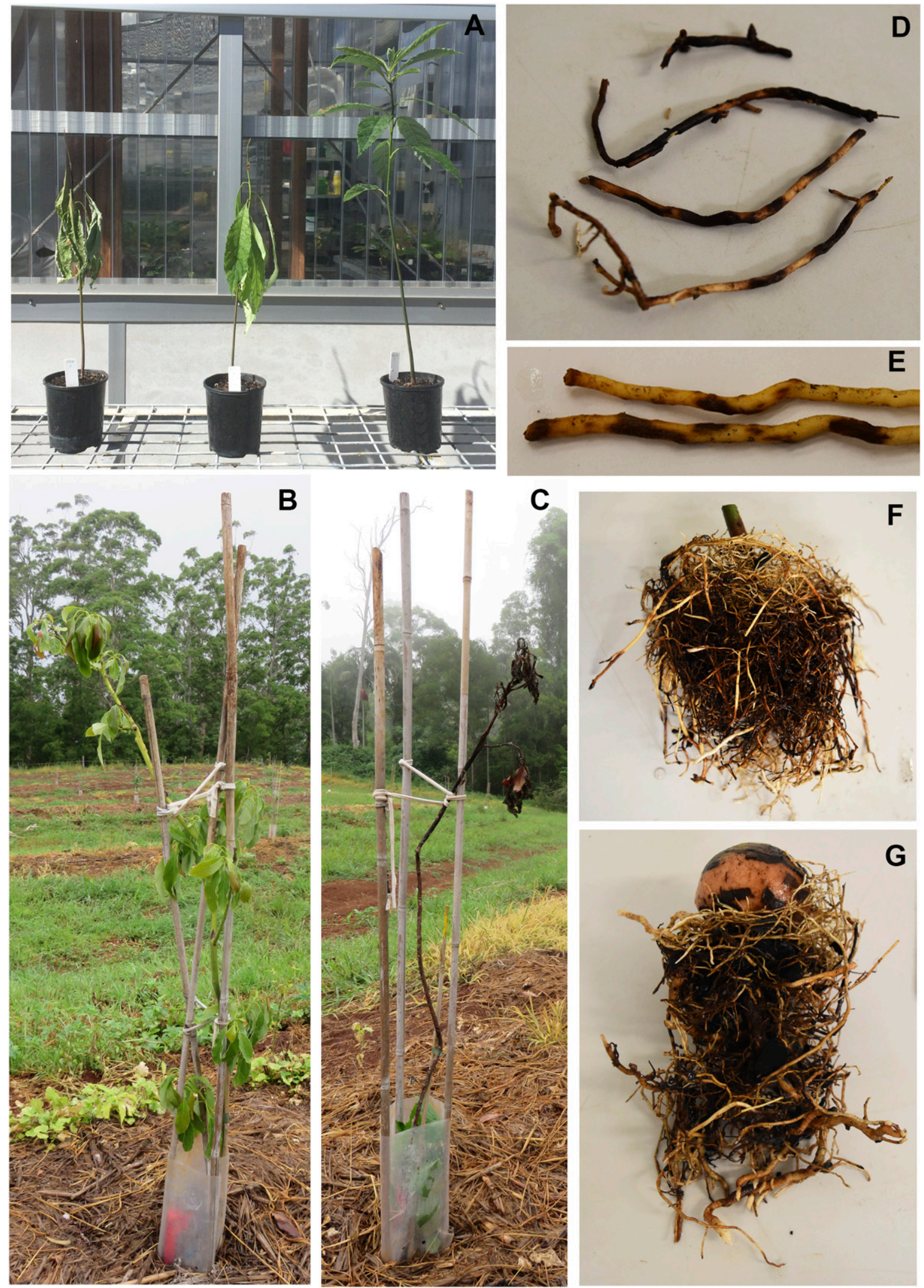

Fig. 1. Symptoms of black root rot disease in avocado seedlings and orchard transplants. A, Leaf wilt and tree stunting in Reed avocado seedlings 5 weeks after inoculation with Calonectria ilicicola compared with uninoculated seedling. Black root rot symptoms in 1-year-old avocado orchard transplants: B, leaf wilt followed by $\mathbf{C}$, rapid death. $\mathbf{D}$ and $\mathbf{E}$, Characteristic black, necrotic root lesions caused by nectriaceous pathogens, which coalesce to rot the entire root. Avocado black root rot symptoms after 9 weeks of inoculation with $\mathbf{F}$, C. ilicicola and $\mathbf{G}$, Dactylonectria macrodidyma. 
This investigation tested several Australian isolates from the nectriaceous genera Calonectria, Dactylonectria, Ilyonectria, Gliocladiopsis, and Cylindrocladiella in experiments for pathogenicity in avocado roots.

\section{MATERIALS AND METHODS}

Isolate identification and inoculum preparation. Nineteen fungal isolates from the genera Calonectria, Cylindrocladiella, Dactylonectria, Gliocladiopsis, and Ilyonectria (Table 1) were chosen for pathogenicity tests. The isolates included species from diseased roots of nursery and field plants of avocado, blueberry, custard apple, grapevine, papaya, and peanut. The isolates were cultured on half-strength potato dextrose agar amended with streptomycin (sPDA) and kept at room temperature under black light ( $12 \mathrm{~h}$ of black light and $12 \mathrm{~h}$ of darkness) for 7 days prior to preparation of inoculum for glasshouse experiments and DNA extractions.

The fungal inoculum contained four $1-\mathrm{cm}^{2}$ sPDA cubes of the respective fungal isolate, which were added to separate 2-liter flasks containing autoclaved media consisting of $200 \mathrm{~g}$ of sand, $20 \mathrm{~g}$ of bran, and $80 \mathrm{ml}$ of water (ratio 10:1:4 [wt/wt]) (Dann et al. 2012), maintained at room temperature on a laboratory bench, and shaken daily for 7 to 10 days to distribute the inoculum evenly.

Isolates were identified by morphology; partial gene sequencing of $\beta$-tubulin, histone $\mathrm{H} 3$, and internal transcribed spacer (ITS) regions 1 and 2 and the $5.8 \mathrm{~S}$ gene of the ribosomal RNA; and phylogenetic analyses.
DNA was extracted from fungal mycelia from cultures grown on sPDA for 7 to 10 days using the Promega Wizard genomic DNA purification kit (Promega Corp. 2010), with modifications to the protocol, including 50 to $100 \mathrm{mg}$ of hyphae ground in $600 \mu \mathrm{l}$ of nuclei lysis solution by tissue lysis (Tissue Lyser; Qiagen) at 30 shakes/s for 3 to $6 \mathrm{~min}$ or by hand with a microfuge tube pestle. DNA extracts of $50 \mathrm{ng} / \mu \mathrm{l}$, measured with a BioDrop spectrophotometer (Dhanoya 2012), were selected as DNA templates for polymerase chain reaction (PCR).

The ITS, $\beta$-tubulin, and histone $\mathrm{H} 3$ gene loci for each isolate were amplified in PCR with $1 \mathrm{U}$ of Invitrogen Taq polymerase, $0.6 \mu \mathrm{M}$ forward primer, $0.6 \mu \mathrm{M}$ reverse primer, $0.2 \mathrm{mM}$ each DNTP, $1.5 \mathrm{mM} \mathrm{MgCl}_{2}$, and $1 \times \mathrm{PCR}$ buffer. The PCR primers used included ITS5 and ITS4 (White et al. 1990) for amplifying $600 \mathrm{bp}$ of the ITS region; T1 (O'Donnell and Cigelnik 1997) and CYLTUB1R (Crous et al. 2004) for amplifying $600 \mathrm{bp}$ of the partial $\beta$-tubulin gene; and CYLH3F and CYLH3R (Crous et al. 2004) for amplifying 500 bp of the partial histone $\mathrm{H} 3$ gene.

Thermal cycling consisted of initial denaturation at $95^{\circ} \mathrm{C}$ for $2 \mathrm{~min}$; followed by 30 cycles of denaturation at $95^{\circ} \mathrm{C}$ for $30 \mathrm{~s}$, annealing at $62^{\circ} \mathrm{C}$ for $30 \mathrm{~s}$, and extension at $72^{\circ} \mathrm{C}$ for $1 \mathrm{~min}$; and terminated at $72^{\circ} \mathrm{C}$ for $5 \mathrm{~min}$. Amplicons were sent to Macrogen Inc. (Republic of Korea) for sequencing.

Approximate genus identities were determined from consensus sequences using a Basic Local Alignment Search Tool (National Center for Biotechnology Information; https://www.ncbi.nlm.nih. gov/). Multiple alignments of three gene loci were performed on the sequences of interest and sequences from type species were

TABLE 1. List of fungal isolates tested in glasshouse pathogenicity experiments

\begin{tabular}{|c|c|c|c|c|c|c|}
\hline Fungal species & $\mathrm{BRIP}^{\mathrm{y}}$ & Host & Locality, state ${ }^{z}$ & $\begin{array}{l}\text { Approximate age of plant, } \\
\text { health }\end{array}$ & $\begin{array}{l}\text { Place of } \\
\text { collection }\end{array}$ & $\begin{array}{l}\text { Substrate } \\
\text { collector }\end{array}$ \\
\hline Calonectria sp. & 60981 & Vaccinium sp. & NSW & Unknown, diseased & Field & E. K. Dann \\
\hline \multirow[t]{6}{*}{ Calonectria ilicicola } & $53933 a$ & Carica papaya & $\begin{array}{l}\text { South Johnstone, } \\
\text { QLD }\end{array}$ & Unknown, diseased & Field & P. Ibell \\
\hline & $54018 \mathrm{a}$ & $\begin{array}{l}\text { Persea } \\
\text { americana }\end{array}$ & QLD & $\begin{array}{l}\text { Young potted nursery tree, } \\
<1 \text { year old, diseased }\end{array}$ & Nursery & $\begin{array}{l}\text { E. K. Dann, A. W. Cooke, } \\
\text { L. I. Forsberg (Dann et al. } \\
\text { 2012) }\end{array}$ \\
\hline & 60389 & $\begin{array}{l}\text { Arachis } \\
\quad \text { hypogaea }\end{array}$ & Tolga, QLD & Unknown, diseased & Field & L. Owens \\
\hline & 60982 & P. americana & Woombye, QLD & $\begin{array}{l}\text { Young potted nursery tree, } \\
<1 \text { year old, diseased }\end{array}$ & Nursery & A. W. Cooke, A. G. Manners \\
\hline & 60992 & C. papaya & $\begin{array}{l}\text { South Johnstone, } \\
\text { QLD }\end{array}$ & Unknown, diseased & Nursery & L.L. Vawdrey \\
\hline & 61291 & $\begin{array}{l}\text { Annona } \\
\quad \text { reticulata }\end{array}$ & Woombye, QLD & $\begin{array}{l}\text { Young potted nursery tree, } \\
<1 \text { year old, diseased }\end{array}$ & Nursery & A. G. Manners \\
\hline $\begin{array}{l}\text { Cylindrocladiella } \\
\text { pseudoinfestans }\end{array}$ & 60986 & P. americana & Woombye, QLD & $\begin{array}{l}\text { Young potted nursery tree, } \\
<1 \text { year old, diseased }\end{array}$ & Nursery & L. McDonald \\
\hline \multirow[t]{4}{*}{$\begin{array}{l}\text { Dactylonectria } \\
\text { macrodidyma }\end{array}$} & $61294 a$ & P. americana & Alstonville, NSW & $\begin{array}{l}\text { Established orchard tree, } \\
>20 \text { years old, diseased }\end{array}$ & Orchard & L. E. Parkinson \\
\hline & $61294 b$ & P. americana & Alstonville, NSW & $\begin{array}{l}\text { Established orchard tree, } \\
>20 \text { years old, diseased }\end{array}$ & Orchard & L. E. Parkinson \\
\hline & $61349 \mathrm{e}$ & P. americana & $\begin{array}{l}\text { Mullumbimby, } \\
\text { NSW }\end{array}$ & $\begin{array}{l}\text { Young potted nursery tree, } \\
<1 \text { year old, diseased }\end{array}$ & Nursery & L. E. Parkinson \\
\hline & $62001 b$ & P. americana & Robinvale, VIC & $\begin{array}{l}\text { Established orchard tree, } \\
<1 \text { year old, diseased }\end{array}$ & Orchard & L. E. Parkinson \\
\hline $\begin{array}{l}\text { Dactylonectria } \\
\text { novozelandica }\end{array}$ & $62000 d$ & P. americana & Gol Gol, NSW & $\begin{array}{l}\text { Young potted nursery tree, } \\
<1 \text { year old, diseased }\end{array}$ & Nursery & L. E. Parkinson \\
\hline $\begin{array}{l}\text { Dactylonectria } \\
\text { pauciseptata }\end{array}$ & $61428 d$ & P. americana & Nimbin, NSW & $\begin{array}{l}\text { Established orchard tree, } \\
<1 \text { year old, diseased }\end{array}$ & Orchard & L. E. Parkinson \\
\hline $\begin{array}{l}\text { Dactylonectria } \\
\text { anthuriicola }\end{array}$ & 60985 & P. americana & Hampton, QLD & $\begin{array}{l}\text { Established orchard tree, } \\
>8 \text { years old, healthy }\end{array}$ & Orchard & K. G. Pegg, L. E. Parkinson \\
\hline \multirow[t]{2}{*}{ Gliocladiopsis peggii } & 60987 & P. americana & Walkamin, QLD & $\begin{array}{l}\text { Young potted nursery tree, } \\
<1 \text { year old, diseased }\end{array}$ & Nursery & K. G. Pegg \\
\hline & 60990 & P. americana & Woombye, QLD & $\begin{array}{l}\text { Young potted nursery tree, } \\
<1 \text { year old, diseased }\end{array}$ & Nursery & A. G. Manners \\
\hline Ilyonectria $\mathrm{sp}$. & $53498 a$ & Vitis vinifera & $\begin{array}{l}\text { Hunter Valley, } \\
\text { NSW }\end{array}$ & Unknown, diseased & Vineyard & Unknown \\
\hline Ilyonectria sp. & $61349 d$ & P. americana & $\begin{array}{l}\text { Mullumbimby, } \\
\text { NSW }\end{array}$ & $\begin{array}{l}\text { Young potted nursery tree, } \\
<1 \text { year old, diseased }\end{array}$ & Nursery & L. E. Parkinson \\
\hline
\end{tabular}

y Culture accession number.

z States in Australia: QLD = Queensland, NSW = New South Wales, and VIC = Victoria. 
downloaded from GenBank. Fungal species identities were confirmed with congruent maximum-likelihood and Bayesian inference phylogenetic trees of partitioned gene loci (data not shown in this study).

Pathogenicity tests. There were three separate pathogenicity experiments, with two replicate trials per experiment, each with 10 (experiments 1 and 3) or 12 (experiment 2) plants per treatment (isolate tested). 'Reed' avocado test plants were grown from seed in the glasshouse (approximately 22 to $24^{\circ} \mathrm{C}$ [day] and $18^{\circ} \mathrm{C}$ [night]) for 3 to 6 months, until seedlings were approximately 30 to $40 \mathrm{~cm}$ high.

Potting soil (Searles Premium Potting Mix) was added to the bottom $3 \mathrm{~cm}$ of each plant pot (12.5 $\mathrm{cm}$ in diameter). Inoculum from flasks was mixed with vermiculite (grade 3) at a 3:1 ratio (percent vol/vol) of vermiculite/inoculum, filling each 2-liter flask; then, approximately 165 to $200 \mathrm{ml}$ of the mixture was distributed into the pots for each treatment group or isolate. A single avocado seedling was transplanted into each pot, with the roots touching the inoculum, and the pots were filled with potting soil. Plant height (top of the seed to the plant apex) was measured immediately after transplantation, then weekly, and any visible disease symptoms were recorded. At 5 weeks (experiments 1 and 3) or 9 weeks (experiment 2) postinoculation, the seedlings were uprooted, the roots were washed to remove potting mixture, and the percentage of necrotic or discolored roots relative to total roots was assessed for each plant. Plant (leaves and stems) and roots were weighed, dried at $55^{\circ} \mathrm{C}$ for 3 days, and reweighed. The causal agents were confirmed by surface sterilizing fresh root samples in $50 \%$ ethanol and plating on sPDA from three to four representative plants of each tested isolate, and observing the fungal morphological structures under a light microscope after 4 to 6 days of growth under black light (12 h of black light and $12 \mathrm{~h}$ of darkness) at room temperature.

Experiment 1: Pathogenicity testing of Calonectria and Ilyonectria spp. The isolates included C. ilicicola (BRIP 54018a), collected from symptomatic nursery avocado (P. americana), which was used as a positive control for disease symptom development in all experiments, and nectriaceous species from other hosts on which the isolates caused disease; for example, $C$. ilicicola from custard apple (Annona reticulata) (BRIP 61291), peanut (Arachis hypogaea) (BRIP 60389), and papaya (Carica papaya) (BRIP 60992 and BRIP 53933a); an undescribed Calonectria sp. from blueberry (Vaccinium sp.) (BRIP 60981); and an undescribed Ilyonectria sp. from grapevine (V. vinifera) (BRIP 53498a) (Table 1).

Experiment 2: Pathogenicity testing of Calonectria, Dactylonectria, and Ilyonectria spp. The isolates tested were collected from symptomatic avocado (1 year old) nursery trees and young orchard transplants (mostly $<1$ year old; two isolates $>20$ years old) and one established healthy orchard tree ( $>8$ years old) (Table 1$)$, including four D. macrodidyma isolates (BRIP 61294a, BRIP 61294b, BRIP 61349e, and BRIP 62001b), D. novozelandica (BRIP 62000d),
D. pauciseptata (BRIP 61428d), D. anthuriicola (BRIP 60985), Ilyonectria sp. (BRIP 61349d), and C. ilicicola (BRIP 54018a) (Table 1).

Experiment 3: Pathogenicity testing of Calonectria, Cylindrocladiella, and Gliocladiopsis spp. The isolates tested in this experiment were collected from symptomatic nursery avocado trees and included one Cylindrocladiella pseudoinfestans isolate (BRIP 60986), two G. peggii isolates (BRIP 60987 and BRIP 60990), and C. ilicicola (BRIP 54018a) (Table 1).

Statistical analyses. The data from each experimental trial were pooled because there was no significant treatment $\times$ trial interaction. The statistical analysis of pooled means was performed using the software GenStat (16th edition; VSN International Ltd.). Plant heights over time, plant and root biomasses, and percentage of necrotic roots were each analyzed by analysis of variance. Fisher's least significant difference was used to rank the means.

\section{RESULTS}

Experiment 1: Pathogenicity testing of Calonectria and Ilyonectria spp. The effects of inoculation with Calonectria and Ilyonectria isolates on avocado were tested in the glasshouse over 5 weeks. A significant difference between the mean plant heights was observed at 4 weeks postinoculation $(P<0.001)$ (data not shown). At 5 weeks postinoculation, all $C$. ilicicola isolates caused significant $(P<0.001)$ stunting in seedlings (Fig. 1; Table 2). Plants inoculated with a Calonectria sp. (BRIP 60981) from blueberry and an Ilyonectria sp. (BRIP 53498a) from grapevine were not significantly different in height from the uninoculated controls (Table 2).

At 5 weeks postinoculation, all $C$. ilicicola isolates significantly reduced leaf and stem biomass (Table 2) compared with uninoculated plants. Leaf and stem biomass of plants inoculated with a Calonectria sp. from blueberry and an Ilyonectria sp. from grapevine were not significantly different from that of plants grown in uninoculated media (Table 2).

All C. ilicicola isolates significantly reduced root biomass compared with uncolonized control media, with an approximately $74 \%$ average reduction in fresh weight (Table 2). The largest reductions in root biomass was caused by inoculation with C. ilicicola isolated from avocado (BRIP 54018a), custard apple (BRIP 61291), peanut (BRIP 60389), and papaya (BRIP 53933a). There was significant variation in root biomass and necrosis between the two $C$. ilicicola isolates from papaya, despite both papaya isolates significantly reducing root biomass compared with uninoculated controls (Table 2). The average root biomass of plants inoculated with a Calonectria sp. (BRIP 60981) or an Ilyonectria sp. (BRIP 53498a) was not statistically different from those from uninoculated plants (Table 2).

All Calonectria isolates caused significantly greater avocado root necrosis than uncolonized media, with $C$. ilicicola isolated

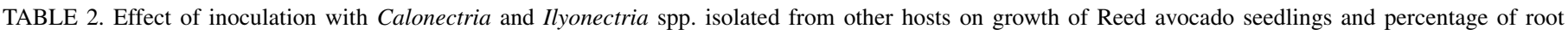
necrosis at 5 weeks after inoculation ${ }^{y}$

\begin{tabular}{|c|c|c|c|c|c|c|c|c|}
\hline \multirow[b]{2}{*}{ Inoculum } & \multirow[b]{2}{*}{$\mathrm{BRIP}^{\mathrm{z}}$} & \multirow[b]{2}{*}{ Host } & \multirow[b]{2}{*}{ Plant height $(\mathrm{cm})$} & \multicolumn{2}{|c|}{ Leaf + stem biomass $(\mathrm{g})$} & \multicolumn{2}{|c|}{ Root biomass (g) } & \multirow[b]{2}{*}{ Root necrosis (\%) } \\
\hline & & & & Fresh & Dry & Fresh & Dry & \\
\hline Uncolonized media & & & $27.5 \mathrm{a}$ & $17.0 \mathrm{a}$ & $4.75 \mathrm{a}$ & $16.6 \mathrm{ab}$ & $2.18 \mathrm{a}$ & $14.6 \mathrm{~d}$ \\
\hline Calonectria ilicicola & $54018 a$ & Persea americana & $21.1 \mathrm{c}$ & $8.17 \mathrm{~d}$ & $2.72 \mathrm{c}$ & $4.33 \mathrm{~d}$ & $0.57 \mathrm{c}$ & $81.3 \mathrm{a}$ \\
\hline Calonectria $\mathrm{sp}$ & 60981 & Vaccinium sp. & $26.0 \mathrm{ab}$ & $15.9 \mathrm{a}$ & $4.56 \mathrm{a}$ & $14.8 \mathrm{bc}$ & $1.94 \mathrm{ab}$ & $27.6 \mathrm{bc}$ \\
\hline C. ilicicola & 61291 & Annona reticulata & $21.3 \mathrm{c}$ & $8.78 \mathrm{~cd}$ & $2.88 \mathrm{c}$ & $6.61 \mathrm{~d}$ & $0.80 \mathrm{c}$ & $70.5 \mathrm{a}$ \\
\hline C. ilicicola & 60389 & Arachis hypogaea & $22.4 \mathrm{bc}$ & $8.46 \mathrm{~d}$ & $2.98 \mathrm{c}$ & $4.09 \mathrm{~d}$ & $0.54 \mathrm{c}$ & $79.1 \mathrm{a}$ \\
\hline C. ilicicola & $53933 a$ & Carica papaya & $21.4 \mathrm{c}$ & $9.64 \mathrm{~cd}$ & $3.10 \mathrm{bc}$ & $4.72 \mathrm{~d}$ & $0.58 \mathrm{c}$ & $79.1 \mathrm{a}$ \\
\hline C. ilicicola & 60992 & C. papaya & $23.1 \mathrm{bc}$ & $12.0 \mathrm{bc}$ & $3.44 \mathrm{bc}$ & $11.5 \mathrm{c}$ & $1.56 \mathrm{~b}$ & $31.4 \mathrm{~b}$ \\
\hline Ilyonectria sp. & $53498 a$ & Vitis vinifera & $23.6 \mathrm{abc}$ & $14.0 \mathrm{ab}$ & $3.97 \mathrm{ab}$ & $18.6 \mathrm{a}$ & $2.35 \mathrm{a}$ & $17.2 \mathrm{~cd}$ \\
\hline
\end{tabular}

y Mean values within columns with the same letter are not significantly different $(P<0.001)$.

$\mathrm{z}$ BRIP accession of fungal isolate. 
from peanut (BRIP 60389), papaya (BRIP 53933a), custard apple (BRIP 61291), and avocado (BRIP 54018a) causing the most severe necrosis. Although the biomass of roots inoculated with the blueberry Calonectria isolate were similar to uninoculated roots, the percentage of necrotic roots was significantly higher (Table 2). The percentage of symptomatic avocado roots in plants inoculated with an Ilyonectria sp. isolated from grapevine (BRIP 53498a) was not significantly different from that of uninoculated avocado plants (Table 2).

Experiment 2: Pathogenicity testing of Calonectria, Dactylonectria, and Ilyonectria spp. The effects of inoculation with C. ilicicola, Dactylonectria spp., and Ilyonectria isolates on avocado were tested in the glasshouse over 9 weeks. A significant difference between the mean plant heights was observed from 6 weeks postinoculation $(P<0.001)$ (data not shown), where plants inoculated with $C$. ilicicola were significantly shorter than uninoculated plants or those inoculated with an Ilyonectria sp. and all isolates of Dactylonectria spp., and remained significantly shorter for the rest of the trial period. By 9 weeks postinoculation, C. ilicicolainoculated plants were $24 \%$ shorter than uninoculated plants (Table 3 ). Plants inoculated with an Ilyonectria sp. or Dactylonectria spp. were not significantly different from uninoculated plants across all time periods. However, at 9 weeks, wilting was observed in some plants inoculated with D. macrodidyma (BRIP 61349e and BRIP 61294a), D. pauciseptata (BRIP 61428d), and C. ilicicola (BRIP 54018a) (data not shown).

Plants inoculated with $C$. ilicicola had significantly reduced fresh weight and dry weight leaf and stem biomass compared with uninoculated plants, with a 33.5 to $33.6 \%$ biomass reduction (Table 3). Plants inoculated with D. macrodidyma (BRIP 61349e) were statistically similar in leaf and stem biomass to C. ilicicola, with a 16.6 to $18.7 \%$ reduction in fresh weight and dry weight, respectively. However, Dactylonectria spp. and the Ilyonectria sp. did not cause significant stunting or a reduction in biomass compared with uninoculated controls (Table 3). Root biomass of plants inoculated with C. ilicicola, an Ilyonectria sp., and Dactylonectria spp. were not significantly different from uninoculated plants $(P=0.071)$.

Inoculation with $C$. ilicicola and Dactylonectria spp. resulted in reduced avocado root health (Fig. 1), where the percentage of necrotic roots was significantly greater compared with uninoculated plants (Table 3). The percentage of necrotic roots after C. ilicicola inoculation was significantly greater than any other treatment: $2.8 \times$ higher than uninoculated controls and 1.3 to $2.2 \times$ higher than plants inoculated with the Ilyonectria $\mathrm{sp}$. and Dactylonectria spp. Plants inoculated with any of the Dactylonectria isolates had significantly more symptomatic roots than uninoculated controls; while those inoculated with the Ilyonectria sp. had root symptoms similar to those of uninoculated controls (Table 3).

Experiment 3: Pathogenicity testing of Calonectria, Cylindrocladiella, and Gliocladiopsis spp. Glasshouse experiments tested the effects of inoculation with C. ilicicola, Cylindrocladiella pseudoinfestans, and G. peggii isolates on avocado seedlings over 5 weeks (Table 4). A significant difference between the mean plant heights was observed at 5 weeks postinoculation, where plants inoculated with $C$. ilicicola (BRIP 54018a) were significantly shorter than the uninoculated group and those inoculated with all other isolates $(P<0.001)$. The height of plants inoculated with C. ilicicola (BRIP 60982), Cylindrocladiella pseudoinfestans (BRIP 60986), and G. peggii (BRIP 60987 and BRIP 60990) was not significantly different from uninoculated plants or each other. However, plants inoculated with G. peggii (BRIP 60987) were significantly taller than the plants inoculated with $C$. ilicicola (BRIP60982).

Plants inoculated with C. ilicicola (BRIP 54018a and BRIP 60982) had significantly lower biomass compared with uninoculated controls (Table 4), with a 52\% reduction in fresh leaf and stem

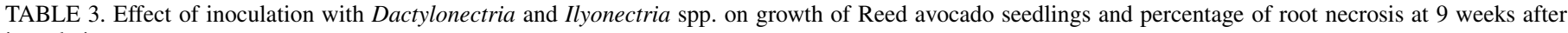
inoculation ${ }^{\mathrm{y}}$

\begin{tabular}{|c|c|c|c|c|c|c|c|}
\hline \multirow[b]{2}{*}{ Inoculum } & \multirow[b]{2}{*}{$\mathrm{BRIPz}^{2}$} & \multirow[b]{2}{*}{ Plant height $(\mathrm{cm})$} & \multicolumn{2}{|c|}{ Leaf + stem biomass $(\mathrm{g})$} & \multicolumn{2}{|c|}{ Root biomass (g) } & \multirow[b]{2}{*}{ Root necrosis $(\%)$} \\
\hline & & & Fresh & Dry & Fresh & Dry & \\
\hline Uncolonized media & $\ldots$ & $38.6 \mathrm{ab}$ & $35.1 \mathrm{ab}$ & $11.3 \mathrm{ab}$ & 26.9 & 2.93 & $20.6 \mathrm{~d}$ \\
\hline Calonectria ilicicola & $54018 \mathrm{a}$ & $29.3 \mathrm{c}$ & $23.3 \mathrm{c}$ & $7.55 \mathrm{c}$ & 18.2 & 2.31 & $58.5 \mathrm{a}$ \\
\hline Ilyonectria sp. & $61349 d$ & $36.8 \mathrm{ab}$ & $35.5 \mathrm{ab}$ & $11.1 \mathrm{ab}$ & 25.6 & 2.96 & $26.5 \mathrm{~cd}$ \\
\hline Dactylonectria anthuriicola & 60985 & $38.0 \mathrm{ab}$ & $36.9 \mathrm{a}$ & $12.0 \mathrm{a}$ & 27.5 & 3.31 & $34.5 \mathrm{bc}$ \\
\hline D. macrodidyma & $61294 a$ & $36.4 \mathrm{ab}$ & $32.8 \mathrm{ab}$ & $10.3 \mathrm{ab}$ & 23.8 & 2.73 & $39.9 \mathrm{~b}$ \\
\hline D. macrodidyma & $61294 b$ & $40.0 \mathrm{a}$ & $35.3 \mathrm{ab}$ & $11.2 \mathrm{ab}$ & 25.1 & 2.90 & $33.3 \mathrm{bc}$ \\
\hline D. macrodidyma & $61349 \mathrm{e}$ & $35.5 \mathrm{ab}$ & $29.3 \mathrm{bc}$ & $9.23 \mathrm{bc}$ & 20.9 & 2.42 & $42.8 \mathrm{~b}$ \\
\hline D. macrodidyma & $62001 b$ & $38.6 \mathrm{ab}$ & $35.7 \mathrm{a}$ & $11.3 \mathrm{ab}$ & 25.9 & 2.80 & $39.2 \mathrm{~b}$ \\
\hline D. novozelandica & $62000 d$ & $34.5 \mathrm{~b}$ & $32.4 \mathrm{ab}$ & $10.3 \mathrm{ab}$ & 25.0 & 2.84 & $42.8 \mathrm{~b}$ \\
\hline D. pauciseptata & $61428 d$ & $37.9 \mathrm{ab}$ & $33.8 \mathrm{ab}$ & $10.2 \mathrm{ab}$ & 25.2 & 2.82 & $40.5 \mathrm{~b}$ \\
\hline
\end{tabular}

y Mean values within columns with the same letter are not significantly different $(P<0.001)$.

$\mathrm{z}$ BRIP accession of fungal isolate.

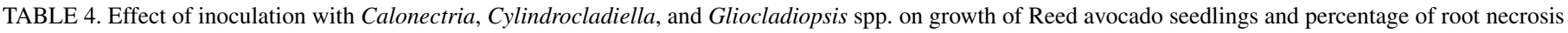
at 5 weeks after inoculation ${ }^{y}$

\begin{tabular}{|c|c|c|c|c|c|c|c|}
\hline \multirow[b]{2}{*}{ Inoculum } & \multirow[b]{2}{*}{ BRIPz } & \multirow[b]{2}{*}{ Plant height $(\mathrm{cm})$} & \multicolumn{2}{|c|}{ Leaf + stem biomass $(\mathrm{g})$} & \multicolumn{2}{|c|}{ Root biomass (g) } & \multirow[b]{2}{*}{ Root necrosis $(\%)$} \\
\hline & & & Fresh & Dry & Fresh & Dry & \\
\hline Uncolonized media & $\ldots$ & $46.9 \mathrm{ab}$ & $21.3 \mathrm{a}$ & $5.84 \mathrm{a}$ & $12.9 \mathrm{~b}$ & $1.31 \mathrm{~b}$ & $22.2 \mathrm{~b}$ \\
\hline Calonectria ilicicola & $54018 \mathrm{a}$ & $38.1 \mathrm{c}$ & $11.1 \mathrm{~b}$ & $3.58 \mathrm{~b}$ & $3.12 \mathrm{c}$ & $0.42 \mathrm{c}$ & $78.1 \mathrm{a}$ \\
\hline C. ilicicola & 60982 & $41.3 \mathrm{abc}$ & $10.2 \mathrm{~b}$ & $3.88 \mathrm{~b}$ & $2.93 \mathrm{c}$ & $0.46 \mathrm{c}$ & $70.6 \mathrm{a}$ \\
\hline Cylindrocladiella pseudoinfestans & 60986 & $45.2 \mathrm{abc}$ & $20.2 \mathrm{a}$ & $5.52 \mathrm{a}$ & $16.3 \mathrm{a}$ & $1.72 \mathrm{a}$ & $30.0 \mathrm{~b}$ \\
\hline Gliocladiopsis peggii & 60987 & $48.2 \mathrm{a}$ & $21.9 \mathrm{a}$ & $5.99 \mathrm{a}$ & $14.8 \mathrm{ab}$ & $1.62 \mathrm{ab}$ & $34.0 \mathrm{~b}$ \\
\hline G. peggii & 60990 & $44.5 \mathrm{abc}$ & $20.0 \mathrm{a}$ & $5.66 \mathrm{a}$ & $14.1 \mathrm{ab}$ & $1.53 \mathrm{ab}$ & $24.9 \mathrm{~b}$ \\
\hline
\end{tabular}

${ }^{y}$ Mean values within columns with the same letter are not significantly different $(P<0.001)$.

$\mathrm{z}$ BRIP accession of fungal isolate. 
biomass and a 77\% reduction in fresh weight root biomass (Table 4). The leaf and stem biomass and root biomass of plants inoculated with $G$. peggii were not significantly different from those from uninoculated plants. The leaf and stem biomass of plants inoculated with Cylindrocladiella pseudoinfestans was not significantly different from uninoculated plants; however, the root biomass of $C$. pseudoinfestans-inoculated plants was significantly higher than uninoculated plants by approximately $21 \%$. Plants inoculated with Calonectria ilicicola had the highest percentage of necrotic roots compared with uninoculated plants, averaging 70 to $78 \%$ necrosis. Severity of root necrosis of Cylindrocladiella or Gliocladiopsisinoculated plants was not significantly different from that of uninoculated plants (Table 4).

All of the isolates were successfully reisolated from the roots in selected plant specimens, fulfilling Koch's postulates. In all three trials, the uninoculated controls showed some measure of root discoloration which contributed to the percentage of necrotic roots in the root assessment. However, no pathogens were isolated from selected uninoculated plant root samples. The root discoloration in uninoculated controls was likely due to suberization rather than necrosis caused by disease.

\section{DISCUSSION}

C. ilicicola was shown to be an aggressive pathogen of avocado seedlings, causing significant root rot, reduced plant and root biomass, stunting, wilt, and death within 5 weeks of inoculation in glasshouse experiments. This confirmed a previous study by Dann et al. (2012), who found significant stunting caused by $C$. ilicicola in 'Velvick' avocado seedlings from 3 to 14 weeks postinoculation and in 'Hass' from 10 to 19 weeks. Contrasting with this study, the Reed seedlings tested in the study by Dann et al. (2012) were not significantly different in height to the uninoculated control group. However, similar to this study, in the Reed plants inoculated with C. ilicicola, significant root rot was found (Dann et al. 2012). C. ilicicola originally isolated from custard apple, papaya, and peanut and a Calonectria sp. from blueberry, caused black root rot disease in avocado seedlings, which demonstrates that these Calonectria spp. are potentially pathogenic to more than one host. The unidentified Calonectria sp. isolated from blueberry was closely related to C. pauciramosa, which Lombard et al. (2011) reported as a dominant nursery pathogen in Australia. Accurate identification of the fungal species responsible for avocado root rot has significant implications for multi-crop production nurseries and orchard disease management strategies.

In this study, D. macrodidyma, D. novozealandica, D. pauciseptata, and $D$. anthuriicola caused significant root rot but did not cause significant stunting in seedlings. A previous study demonstrated that D. macrodidyma was pathogenic to avocado, causing wilting, root rot, and tree death 2 months after inoculation (Vitale et al. 2012); however, plant height was not measured. This is the first report confirming the pathogenicity of $D$. macrodidyma, D. novozelandica, D. pauciseptata, and D. anthuriicola on avocado trees in Australia.

A number of the pathogenic Calonectria and Dactylonectria isolates were collected directly from roots of nursery trees or from young trees that had declined within a year after being transplanted into the orchard. Once nursery stock is contaminated with nectriaceous pathogens, the spread of disease is exacerbated by frequent irrigation (and over-irrigation), crowded seedling arrangements, and poor nursery hygiene practices (Crous 2002). Desiccation and unfavorable environmental conditions for fungal growth have little effect on the primary survival of propagules, microsclerotia, and chlamydospores (Crous 2002; Sinclair and Backman 1989), because these highly resistant resting structures can survive for several years, infesting soil and host debris, and will germinate or sporulate when conditions become favorable (Crous 2002). Clean planting material is critical for preventing young tree deaths after transplanting (Dann et al. 2012, 2013). Australian avocado growers are able to source trees from several nurseries registered and frequently tested under the Australian Avocado Nursery Voluntary Accreditation Scheme and Nursery Industry Accreditation Scheme Australia.

Cylindrocladiella pseudoinfestans and G. peggii isolates from avocado were not pathogenic. C. pseudoinfestans increased root biomass but did not produce taller trees, whereas $G$. peggii did not cause any significant difference from the uninoculated controls. The isolates tested in this study are likely saprobic rhizosphere inhabitants (Lombard and Crous 2012) or root endophytes (Liu and Cai 2013). Cylindrocladiella spp. are generally not regarded as important plant pathogens (Lombard et al. 2012). However, C. parva was associated with avocado roots and cuttings in South Africa (Crous et al. 1991; Darvas 1978; van Coller et al. 2005), and the death of 3-year-old 'Wurtz' trees in Woombye, Australia in the 1980s (Dann et al. 2012). C. parva is reported as a common soil saprobe (Brown et al. 2013) associated with a number of hosts in genera such as Acacia, Eucalyptus, Pinus (Crous et al. 1991), and Vitis (Brown et al. 2013). The pathogenicity of $C$. parva to avocado remains unknown because pathogenicity experiments have never been reported, although based on our findings, it is unlikely to be responsible for severe root disease and tree death.

The undescribed Ilyonectria sp. isolate (BRIP 53498a) from grapevine was closely related to $I$. liriodendri, a pathogen of grapevine (Cabral et al. 2012), whereas the reported I. liriodendri isolate tested in Dann et al. (2012) has subsequently been found to be a potentially novel species, phylogenetically distinct from I. liriodendri (L. E. Parkinson, R. G. Shivas, and E. K. Dann, unpublished data). The other undescribed Ilyonectria sp. (BRIP 61349d) in this study is also a potentially novel species (L. E. Parkinson, R. G. Shivas, and E. K. Dann, unpublished data). Closely related to I. capensis, which causes Ilyonectria black foot rot in members of the family Proteaceae (Lombard et al. 2013). However, both Ilyonectria isolates in this study had no effect on avocado seedlings, consistent with the findings of Dann et al. (2012). Although the tested Ilyonectria isolates were not directly pathogenic, Ilyonectria spp. are also reported as soil saprobes (Agustí-Brisach and Armengol 2013) and their isolation from symptomatic avocado roots may be incidental.

However, there is a possibility that the pathogenic and other nectriaceous fungi found in association with young avocado orchard transplants predispose their hosts to infection by more aggressive pathogens (e.g., Phytophthora cinnamomi). Co-infection studies on grapevine cultivars with Botryosphaeriaceae spp. and I. liriodendri or D. macrodidyma significantly increased black foot disease severity compared with inoculation with I. liriodendri or D. macrodidyma alone (Whitelaw-Weckert et al. 2013). Similarly, synergistic pathogenicity between D. macrodidyma and Pythium irregulare was reported in apple seedlings; co-inoculated plants were significantly reduced in plant weight and height compared with inoculation with these species individually (Tewoldemedhin et al. 2011a). The prevalence of rapid death and decline of young avocado orchard transplants may be explained by previous infection with nectriaceous species in the nursery, followed by secondary infection by aggressive soilborne pathogens in the orchard.

This study found further causal agents of black root rot disease of avocado trees in Australia. Further studies should investigate the facilitation of disease by co-infection of a number of nectriaceous species and investigate other disease management methods to improve current management practices.

\section{ACKNOWLEDGMENTS}

AV14012 was funded by Horticulture Innovation Australia Limited using the avocado levy and funds from the Australian Government. This project is jointly supported by the Queensland Department of Agriculture and Fisheries (DAF) and the University of Queensland. L. E. Parkinson is a recipient of an Australian Postgraduate Award. We thank R. Daniel 
(New South Wales Department of Primary Industries) and P. Trevorrow (DAF) for providing fungal isolates and the avocado nursery operators and growers who kindly allowed us to collect samples to build our isolate collection.

\section{LITERATURE CITED}

Agustí-Brisach, C., and Armengol, J. 2013. Black-foot disease of grapevine: An update on taxonomy, epidemiology and management strategies. Phytopathol. Mediterr. 52:245-261.

Besoain, X., and Piontelli, E. 1999. Black root rot in avocado plants (Persea americana Mill.) by Cylindrocarpon destructans: Pathogenicity and epidemiological aspects. Bol. Micol. 14:41-47.

Boesewinkel, H. J. 1986. New plant disease records from New Zealand. Australas. Plant Pathol. 15:18-21.

Brown, D., Jaspers, M., Ridgway, H., Barclay, C., Jones, E., and Zydenbos, S. 2013. Susceptibility of four grapevine rootstocks to Cylindrocladiella parva. N. Z. Plant Prot. 66:249-253.

Cabral, A., Cecília, R., Crous, P. W., and Oliveira, H. 2012. Virulence and cross-infection potential of Ilyonectria spp. to grapevine. Phytopathol. Mediterr. 51:340-354.

Crous, P. W. 2002. Taxonomy and Pathology of Cylindrocladium (Calonectria) and Allied Genera. The American Phytopathological Society, St. Paul, MN.

Crous, P. W., Groenewald, J. Z., Risède, J.-M., Simoneau, P., and Hywel-Jones, N. L. 2004. Calonectria species and their Cylindrocladium anamorphs: Species with sphaeropedunculate vesicles. Stud. Mycol. 50: 415-430.

Crous, P. W., Phillips, A. J. L., and Wingfield, M. J. 1991. The genera Cylindrocladium and Cylindrocladiella in South Africa, with special reference to forest nurseries. S. Afr. For. J. 157:69-85.

Dann, E. K., Cooke, A. W., Forsberg, L. I., Pegg, K. G., Tan, Y. P., and Shivas, R. G. 2012. Pathogenicity studies in avocado with three nectriaceous fungi, Calonectria ilicicola, Gliocladiopsis sp. and Ilyonectria liriodendri. Plant Pathol. 61:896-902.

Dann, E. K., Ploetz, R. C., Coates, L. M., and Pegg, K. G. 2013. Foliar, fruit and soilborne diseases. Pages 380-422 in: The Avocado: Botany, Production and Uses. B. Schaffer, B. N. Wolstenholme, and A. W. Whiley, eds. CABI, Homestead, FL

Darvas, J. 1978. Common root pathogens from avocados. South African Avocado Growers'. Assoc. Res. Rep. 2:3-4.

Dhanoya, A. 2012. Quantification of microliter volumes of DNA. Genet. Eng. Biotechnol. News 32:32-33.

Halleen, F., Schroers, H., Groenwald, J. Z., and Crous, P. W. 2004. Novel species of Cylindrocarpon (Neonectria) and Campylocarpon gen. nov. associated with black foot disease of grapevines (Vitis spp.). Stud. Mycol. 50: 431-455.

Kuruppu, P. U., Schneider, R. W., and Russin, J. S. 2004. Factors affecting soybean root colonization by Calonectria ilicicola and development of red crown rot following delayed planting. Plant Dis. 88:613-619.

Lechat, C., Groenewald, J. Z., and Crous, P. W. 2010. The enigma of Calonectria species occurring on leaves of Ilex aquifolium in Europe. IMA Fungus 1:101-108.

Liu, F., and Cai, L. 2013. A novel species of Gliocladiopsis from freshwater habitat in China. Cryptogam.: Mycol. 34:233-241.

Lombard, L., Bezuidenhout, C. M., and Crous, P. W. 2013. Ilyonectria black foot rot associated with Proteaceae. Australas. Plant Pathol. 42:337-349.

Lombard, L., and Crous, P. W. 2012. Phylogeny and taxonomy of the genus Gliocladiopsis. Persoonia 28:25-33.

Lombard, L., Crous, P. W., Wingfield, B. D., and Wingfield, M. J. 2010a. Phylogeny and systematics of the genus Calonectria. Stud. Mycol. 66: 31-69.

Lombard, L., Crous, P. W., Wingfield, B. D., and Wingfield, M. J. 2010 b. Species concepts in Calonectria (Cylindrocladium). Stud. Mycol. 66: $1-13$.
Lombard, L., Polizzi, G., Guarnaccia, V., Vitale, A., and Crous, P. W. 2011. Calonectria spp. causing leaf spot, crown and root rot of ornamental plants in Tunisia. Persoonia 27:73-79.

Lombard, L., Shivas, R. G., To-Anun, C., and Crous, P. W. 2012. Phylogeny and taxonomy of the genus Cylindrocladiella. Mycol. Prog. 11:835-868.

Lombard, L., Van Der Merwe, N. A., Groenewald, J. Z., and Crous, P. W. 2014. Lineages in Nectriaceae: Re-evaluating the generic status of Ilyonectria and allied genera. Phytopathol. Mediterr. 53:515-532.

Lombard, L., Van Der Merwe, N. A., Groenewald, J. Z., and Crous, P. W. 2015. Generic concepts in Nectriaceae. Stud. Mycol. 80:189-245.

Male, M. F., Tan, Y. P., Vawdrey, L. L., and Shivas, R. G. 2012. Recovery, pathogenicity and molecular sequencing of Calonectria ilicicola which causes collar rot on Carica papaya in Australia. Australas. Plant Dis. Notes 7:137-138.

Ochi, S., Yoshida, M., Nakagawa, A., and Natsume, M. 2011. Identification and activity of a phytotoxin produced by Calonectria ilicicola, the causal agent of soybean red crown rot. Can. J. Plant Pathol. 33:347-354.

O'Donnell, K., and Cigelnik, E. 1997. Two divergent intragenomic rDNA ITS2 types within a monophyletic lineage of the fungus Fusarium are nonorthologous. Mol. Phylogenet. Evol. 7:103-116.

Parkinson, L. E., Shivas, R. G., and Dann, E. K. 2017. Novel species of Gliocladiopsis (Nectriaceae, Hypocreales, Ascomycota) from avocado roots (Persea americana) in Australia. Mycoscience 58:95-102.

Polizzi, G., Vitale, A., Aiello, D., Guarnaccia, V., Crous, P., and Lombard, L. 2012. First report of Calonectria ilicicola causing a new disease on Laurus (Laurus nobilis) in Europe. J. Phytopathol. 160:41-44.

Promega Corp. 2010. Wizard Genomic DNA Purification Kit Technical Manual. Promega Corp., Madison, WI.

Ramírez-Gil, G., and Morales-Osorio, J. G. 2013. First report of Cylindrocarpon destructans (Zinss) Scholten affecting avocado (Persea americana Mill) seedling in Colombia. Rev. Prot. Veg. 28:27-35.

Sinclair, J., and Backman, P. 1989. Compendium of Soybean Diseases. American Phytopathological Society Press, St. Paul, MN.

Tewoldemedhin, Y. T., Mazzola, M., Labuschagne, I., and McLeod, A. 2011a. A multi-phasic approach reveals that apple replant disease is caused by multiple biological agents, with some agents acting synergistically. Soil Biol. Biochem. 43:1917-1927.

Tewoldemedhin, Y. T., Mazzola, M., Mostert, L., and McLeod, A. 2011 b. Cylindrocarpon species associated with apple tree roots in South Africa and their quantification using real-time PCR. Eur. J. Plant Pathol. 129:637-651.

van Coller, G. J., Denman, S., Groenewald, J. Z., Lamprecht, S. C., and Crous, P. W. 2005. Characterisation and pathogenicity of Cylindrocladiella spp. associated with root and cutting rot symptoms of grapevines in nurseries. Australas. Plant Pathol. 34:489-498.

Vitale, A., Aiello, D., Guarnaccia, V., Perrone, G., Stea, G., and Polizzi, G. 2012. First report of root rot caused by Ilyonectria (=Neonectria) macrodidyma on avocado (Persea americana) in Italy. J. Phytopathol. 160: 156-159.

White, T. J., Bruns, T., Lee, S., and Taylor, J. W. 1990. Amplification and direct sequencing of fungal ribosomal RNA genes for phylogenetics. Pages 315-322 in: PCR Protocols: A Guide to Methods and Applications. M. A. Innis, D. H. Gelfand, J. J. Sninsky, and T. J. White, eds. Academic Press, Inc., New York.

Whitelaw-Weckert, M. A., Rahman, L., Appleby, L. M., Hall, A., Clark, A. C., Waite, H., and Hardie, W. J. 2013. Co-infection by Botryosphaeriaceae and Ilyonectria spp. fungi during propagation causes decline of young grafted grapevines. Plant Pathol. 62:1226-1237.

Wright, L., Davis, A., Wingfield, B., Crous, P., Brenneman, T., and Wingfield, M. 2010. Population structure of Cylindrocladium parasiticum infecting peanuts (Arachis hypogaea) in Georgia, USA. Eur. J. Plant Pathol. 127: 199-206.

Zilberstein, M., Noy, M., Levy, E., Elkind, G., Zeidan, M., Teverovski, E., and Ben Ze'ev, I. 2007. Wilting disease of young avocado trees caused by Neonectria radicicola in Israel. Pages 25-30 in: 6th World Avocado Congr. Proc. Conf. Viña Del Mar, Chile. 